\title{
Acute Homeostatic Responses to Increased Fat Consumption in MCH1R Knockout Mice
}

\author{
Shinjae Chung $\cdot$ Timothy Wong $\cdot$ Hiroshi Nagasaki $•$ \\ Olivier Civelli
}

Received: 9 February 2010 / Accepted: 19 March 2010/Published online: 22 April 2010

(C) The Author(s) 2010. This article is published with open access at Springerlink.com

\begin{abstract}
Melanin-concentrating hormone $(\mathrm{MCH})$ is a hypothalamic neuropeptide which has been shown to regulate energy homeostasis. Using genetic knockout mice lacking the MCH1 receptor (MCH1R), we investigated how these mice adapt to metabolic changes caused by excessive caloric consumption. We show that the $\mathrm{MCH}$ system is one of the players mediating behavioral and metabolic responses upon increased caloric consumption. MCH1R knockout mice showed decreased tendency of food intake upon exposure to a high-fat diet. They also are resistant to gain weight upon high-fat diet by increasing fat metabolism. Therefore, the $\mathrm{MCH}$ system is important in regulating metabolic responses upon various environmental stimuli such as high-fat diet.
\end{abstract}

Keywords Melanin-concentrating hormone - Energy homeostasis $\cdot G$ protein-coupled receptor $\cdot$ Neuropeptide

S. Chung $\cdot$ T. Wong $\cdot$ O. Civelli $(\bowtie)$

Department of Pharmacology, University of California,

369 Med Surge II,

Irvine, CA 92612, USA

e-mail: ocivelli@uci.edu

S. Chung $\cdot$ O. Civelli

Department of Developmental and Cell Biology,

University of California Irvine,

Irvine, CA, USA

O. Civelli

Department of Pharmaceutical Sciences,

University of California Irvine,

Irvine, CA, USA

H. Nagasaki

Department of Metabolic Medicine, School of Medicine,

Nagoya University,

Nagoya, Japan

\section{Introduction}

Melanin-concentrating hormone $(\mathrm{MCH})$ is a cyclic neuropeptide originally isolated from salmon pituitary where it induces paling of the skin (Kawauchi et al. 1983). In rodents and human, $\mathrm{MCH}$ exists as a 19-amino-acid-long peptide which is mainly synthesized in the lateral hypothalamus and the zona incerta (Mouri et al. 1993; Qu et al. 1996; Vaughan et al. 1989). In rodents, MCH interacts with one receptor, MCH1R (Bachner et al. 1999; Chambers et al. 1999; Lembo et al. 1999; Saito et al. 1999; Shimomura et al. 1999). MCH1R is widely expressed in the brain suggesting that the $\mathrm{MCH}$ system might have diverse physiological functions (Bittencourt et al. 1992; Saito et al. 2001). In rodents, $\mathrm{MCH}$ has been shown to regulate energy homeostasis (Pissios et al. 2006). Acute central $\mathrm{MCH}$ administration increases food intake, and chronic administrations increase body weight, white adipose tissue mass, and liver mass in mice (Ito et al. 2003). MCH levels are increased upon fasting and $\mathrm{MCH}$ is overexpressed in the hypothalamus of $o b / o b$ mice (Qu et al. 1996). Mice lacking prepro-MCH are lean due to hypophagia and an increase in metabolic rate (Shimada et al. 1998). MCH1R knockout mice are lean; however, they are hyperphagic and hyperactive (Marsh et al. 2002). Furthermore, MCH1R knockout mice are resistant to diet-induced obesity (Chen et al. 2002). These evidences suggest that MCH is important in regulating energy homeostasis.

To identify specific roles of the $\mathrm{MCH}$ system in coordinating energy homeostasis, we examined the metabolic and behavioral responses of MCH1R knockout (KO) mice subjected to increased dietary fat. This environmental stimulus affects energy homeostasis through the hypothalamic pathways which maintain the integrity of the body's basal metabolism. Since MCH is a hypothalamic peptide 
which has been shown to modulate feeding response and metabolism, we studied its roles in metabolic adaptations to high-fat diet by using mice lacking the MCH1R.

Previous studies have shown that MCH1R KO mice have lower body weight and fat mass than wild-type (WT) mice upon chronic high-fat diet (Chen et al. 2002; Marsh et al. 2002). These studies, however, focused only on the long-term consequences of exposure to high-fat diet (Chen et al. 2002). MCH1R KO mice have been subjected to moderate high-fat (MHF) diet and have exhibited similar level of enhanced running wheel activity to WT mice (Zhou et al. 2005). This suggests that MCH1R is not required for acute activity-based energy expenditure upon a change in diet composition. Our study therefore focused on how acute exposure to high-fat diet affects metabolic adaptations in MCH1R KO mice.

\section{Materials and Methods}

Animals

MCH1R knockout mice obtained from Merck (Marsh et al. 2002), backcrossed to a C57BL/6 backgrounds, were used for all the experiments. Animals were group-housed and maintained on a 12-h light/dark cycle (lights on at 07:00) with food and water available ad libitum. For studies measuring feeding and metabolism, mice were single housed for the accurate measurement of individual animal. All experimental procedures were performed in compliance with NIH Guide for Care and Use of Laboratory Animals and approved by the UCI Institutional Animal Care and Use Committee.

\section{Metabolic Measurements}

$\mathrm{VO}_{2}$ and $\mathrm{VCO}_{2}$ were simultaneously measured by indirect calorimetry (Oxymax, Columbus Instruments, Columbus, $\mathrm{OH}$, USA). Mice were acclimatized to the chamber at least for 2 days. Mice were individually housed in specially built plexiglass cages $(20 \mathrm{~cm} \times 10.5 \mathrm{~cm} \times 12 \mathrm{~cm})$ through which room air is passed at a flow rate of $0.52 \mathrm{l} / \mathrm{min}$. Exhaust air from each chamber will be sampled at 5-min intervals. Sample air was sequentially passed through $\mathrm{O}_{2}$ and $\mathrm{CO}_{2}$ analyzers (Columbus Instruments) for determination of $\mathrm{O}_{2}$ and $\mathrm{CO}_{2}$ content. Metabolic rate (calorie per hour) was calculated from the following equation: $(3.815+1.232 \times$ RER) $\times \mathrm{VO}_{2}$, where RER is the respiratory exchange ratio [volume of $\mathrm{CO}_{2}$ produced $(\mathrm{ml} / \mathrm{kg}$ body weight $/ \mathrm{h})$ per volume of $\mathrm{O}_{2}$ consumed $(\mathrm{ml} / \mathrm{kg}$ body weight $\left./ \mathrm{h})\right]$ and $\mathrm{vO}_{2}$ is the volume of $\mathrm{O}_{2}$ consumed per hour. After they were adapted to the chamber, food was switched to a high-fat diet (HF) diet (D12451, 45\% kcal fat; Research Diets, New
Brunswick, NJ, USA). Mice were left in the chamber three more days to examine any changes in their metabolism.

Data Analysis

Prism software (GraphPad, San Diego, CA, USA) was used for statistical analysis. Results were analyzed by $t$ test or ANOVA followed by the appropriate post hoc comparisons, and $p<0.05$ was considered statistically significant.

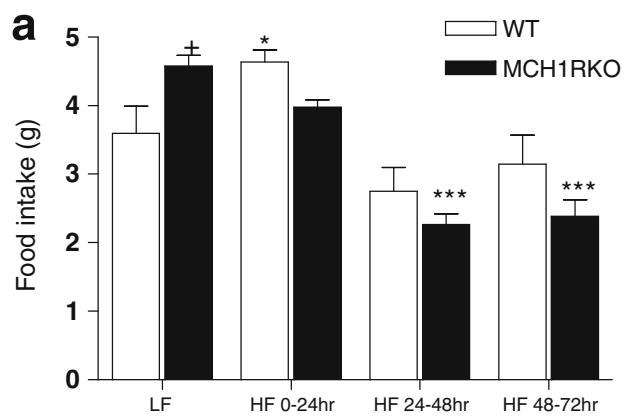

\section{b}
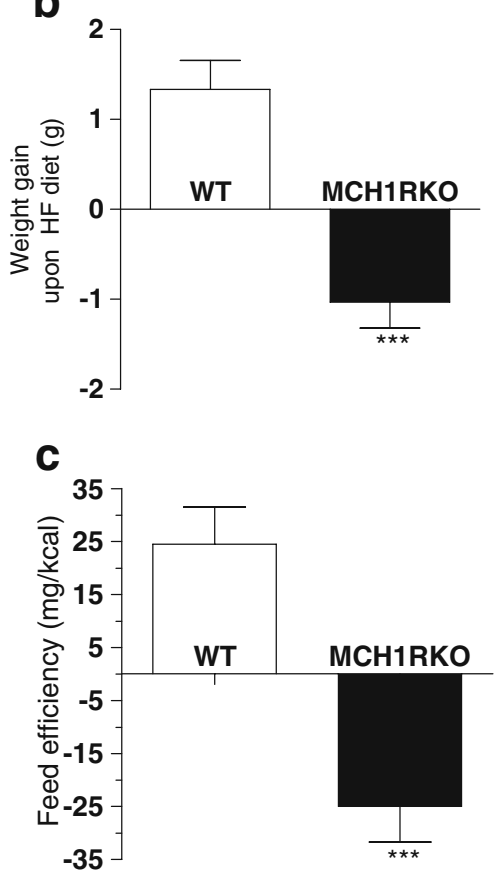

Figure 1 Food intake and feed efficiency of MCH1R knockout mice in response to switching from low-fat $(L F)$ to high-fat $(H F)$ diet. a Food intake pattern during low-fat diet $(L F)$ and 0-24, 24-48, and 48$72 \mathrm{~h}$ after switching to a high-fat diet (HF) in WT (white bars) and MCH1R KO (black bars) mice $(* p<0.05, * * * p<0.001$ compared to LF; $+p<0.05$ compared to WT; two-way ANOVA followed by Bonferroni posttests for multiple comparisons). b Body weight gain in WT and MCH1R KO mice during $72 \mathrm{~h}$ of HF diet $(* * * p<0.001$ compared to WT; unpaired $t$ test). c Feed efficiency of WT and MCH1R KO mice during $72 \mathrm{~h}$ of HF consumption. Feed efficiency was calculated by dividing body weight gain with the amount of calories that each animal consumed over $72 \mathrm{~h}(* * * p<0.001$ compared to WT; unpaired $t$ test) 


\section{Results}

Metabolic Responses of MCH1R Knockout Mice to High Fat Diet Consumption

Acute metabolic responses to changes in caloric content were examined using diets differing in fat contents. WT and MCH1R KO mice that have been raised on a low-fat diet (LF) were placed on a $\mathrm{HF}$ diet. As previously reported (Marsh et al. 2002), MCH1R KO mice were hyperphagic while they were exposed to LF diet $(+p<0.05$ vs. WT; Fig. 1a). In WT mice, transition to the HF diet led to a marked increase in their food consumption, in particular for the first $24 \mathrm{~h}$, perhaps due to novelty or palatability of the HF diet $\left({ }^{*} p<0.05\right.$; Fig. 1a). In contrast, MCH1R KO mice showed decreased feeding tendency. Overall, food intake of MCH1R KO mice, upon switch to a high-fat diet, was slightly lower than the one of WT mice but this was not statistically significant (Fig. 1a). However, WT mice food intake returned to normal levels during 48-72 h of HF diet (in comparison to that on LF diet), whereas that of MCH1R $\mathrm{KO}$ mice was maintained at a significantly lower level $(* * * p<0.001$ compared to LF diet). WT mice increased their body weight upon HF diet whereas MCH1R KO mice lost body weight $(* * * p<0.001$; Fig. 1b). MCH1R KO mice' feed efficiency (weight gain per kilocalorie ingested) was significantly lower than the WT mice fed with HF diet $(* * * p<0.001$; Fig. 1c), suggesting that the KO mice' reduced weight gain may not simply due to hypophagia but due to metabolism.

Diet-induced thermogenesis is proportionate to caloric consumption and represents an important component of energy homeostasis. To study whether the $\mathrm{MCH}$ system regulates diet-induced thermogenesis upon exposure to a high-fat diet, energy expenditure was monitored in WT and MCH1R KO mice when they were exposed to a high-fat diet.

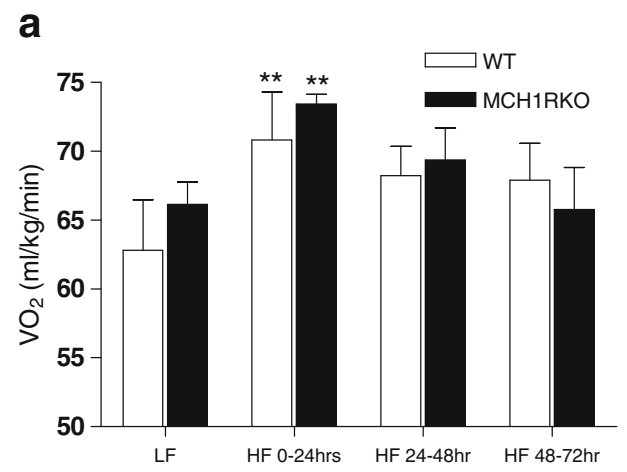

Figure 2 Oxygen consumption $\left(\mathrm{VO}_{2}\right)$ and the respiratory exchange ratio $(R E R)$ of $\mathrm{MCH} 1 \mathrm{R}$ knockout mice in response to switching from low-fat $(L F)$ to high-fat $(H F)$ diet. a $\mathrm{VO}_{2}$ in response to switching from low-fat diet to high-fat $\operatorname{diet}(* * p<0.01$ compared to LF; two-way
Exposure to $\mathrm{HF}$ diet significantly increased oxygen consumption $\left(\mathrm{VO}_{2}\right)$ in both WT and MCH1R KO mice during the first $24 \mathrm{~h}(* * p<0.01$ compared to LF; Fig. 2a). WT mice still showed slightly increased tendency of $\mathrm{VO}_{2}$ during $\mathrm{HF}$ 24-72 h. However, $\mathrm{VO}_{2}$ of MCH1R KO mice during 48-72 h of HF returned to basal levels. This level is similar to the one while they were fed with LF diet. The respiratory exchange ratio ( $\mathrm{RER} ; \mathrm{VCO}_{2} / \mathrm{VO}_{2}$ ) is another parameter measuring metabolism and is an indirect measure of the ratio of carbohydrates and fats being oxidized to fuel metabolism. High RER indicates decreased utilization of fatty acids relative to carbohydrates and a low RER indicates increased fat utilization (Ferrannini 1988). Previous studies show that low fatty acid oxidation is a risk factor for the development of obesity. During the first $24 \mathrm{~h}$ of HF diet, RER increased significantly in WT mice $(* p<0.05$ compared to LF), presumably due to acute influx of carbohydrates. In contrast, RER of MCH1R KO mice decreased significantly $(* * p<0.01$ compared to LF) which suggests that the $\mathrm{KO}$ mice increased their fat utilization. After $48-72 \mathrm{~h}$ of HF diet, the RER of the WT mice returned to their baseline whereas that of the MCH1R KO mice remained significantly low (***p $<0.001$ compared to LF; Fig. 2b).

These data indicate that reduced feed efficiency of the MCH1R KO mice upon high-fat diet is not caused by a decrease in appetite alone. It correlates with an increased fatty acid oxidation which is evidenced by their lower RER value (Fig. 2b). This suggests that blockade of the endogenous MCH system might boost fat burning process upon increased dietary fat consumption and that this might have caused the resistance to body weight gain in $\mathrm{MCH} 1 \mathrm{R} \mathrm{KO}$ mice.

\section{Discussion}

The MCH system has been extensively studied for its roles in regulating energy homeostasis (Pissios et al. 2006).

\section{b}

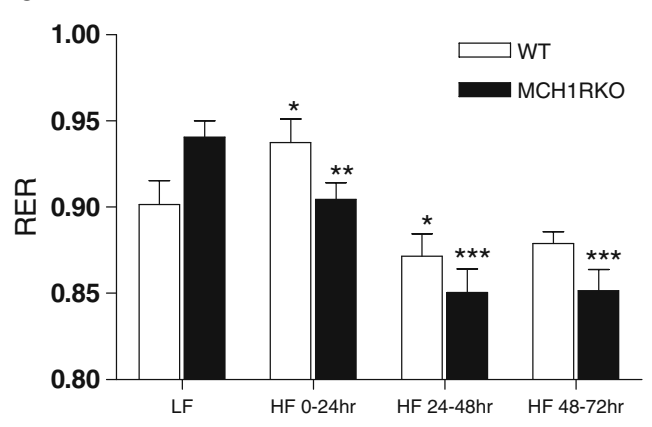

ANOVA followed by Bonferroni posttests for multiple comparisons). b RER in response to switching from low-fat to high-fat diet $\left(^{*} p<\right.$ $0.05, * * p<0.01, * * * p<0.001$ compared to LF; two-way ANOVA followed by Bonferroni posttests for multiple comparisons) 
These data have suggested that the MCH system may be involved in many situations where energy homeostasis is perturbed. We chose to study the MCH system's potential role in diet-induced thermogenesis induced by increased dietary fat consumption. This stimulus has been shown to affect the hypothalamic pathway which maintains homeostasis. In this report, we use MCH1R KO mice to show that the $\mathrm{MCH}$ system is involved in maintaining homeostasis when animals are exposed to increased fat consumption.

We show that the MCH system is involved in the adaptation to high-fat diet provided acutely. When they were fed with normal chow, MCH1R KO mice showed hyperphagia as previously described, possibly secondary to their increased metabolism and activity (Marsh et al. 2002). In young and lean animals, transition from low- to high-fat diet leads to a marked hyperphagia due to the novelty and palatability of the high-fat diet. This transition is then followed by a reduced food intake to account for the higher energy content of the diet. MCH1R KO mice, however, did not exhibit hyperphagia but instead an immediate reduction in food intake. This suggests that MCH1R KO mice do not show a tendency to prefer high-fat diet. Most notably, the feed efficiency of MCH1R KO mice during the $72 \mathrm{~h}$ of HF diet was significantly lower than that of WT mice which suggests that the $\mathrm{MCH}$ system might regulate metabolic responses upon exposure to high-fat diet. This led us to monitor the acute metabolic changes of these mice upon highfat diet consumption by monitoring their RER and $\mathrm{VO}_{2}$.

When exposed to high calorific food in mice, $\mathrm{VO}_{2}$ increases due to increase in locomotor activity. Both WT and MCH1R KO mice have been shown to exhibit an increase in locomotor activity upon transition to a MHF diet (Zhou et al. 2005), but the effect on $\mathrm{VO}_{2}$ was not reported. Our results show no significant difference in the $\mathrm{VO}_{2}$ of MCH1R KO mice upon exposure to high-fat diet. This is surprising especially since mice lacking $\mathrm{ppMCH}$ exhibit a higher $\mathrm{VO}_{2}$ and a higher locomotor activity after $24 \mathrm{~h}$ of high-fat diet than WT mice (Kokkotou et al. 2005). It may, however, be explained at least in part by our RER results. RER values represent the energy fuel that animals use. High RER indicates increased utilization of carbohydrates for energy consumption whereas low RER indicates increased utilization of fatty acids. Therefore, high RER values in animals lead to increased risk of weight gain. Transition to HF diet usually decreases RER values to increase fat oxidation so that animals do not gain weight. Our study shows that RER values of WT mice increased significantly during the first 24-h HF diet before decreasing during the $24-72 \mathrm{~h}$ of HF diet, as expected. On the other hand, the RER values of MCH1R KO mice subjected to the same paradigm are high on LF diet and gradually decrease when put on HF diet. They do not show the burst in increase in the first $24 \mathrm{~h}$ of HF diet as do the WT mice. This suggests that the MCH1R KO mice can increase fat oxidation more efficiently. This might also have contributed to the resistance to weight gain in MCH1R KO mice upon HF diet. This finding suggests that the MCH system can modulate fat/carbohydrate oxidation, especially when animals are acutely exposed to HF diet. This is in agreement with the studies that have reported that MCH1R antagonists induce significant weight loss than a pair-fed group (Huang et al. 2005; Ito et al. 2010). Ito et al. reported that chronic MCH1R antagonist treatments into DIO mice slightly increased fatty acid oxidation and reduced serum-free fatty acid level, but not triglyceride level (Ito et al. 2010). These findings suggest that MCH1R signaling modulates fatty acid oxidation when animals are exposed to HF diet. Also, it has been reported that MCH1R KO mice have slightly lower triglyceride level than WT mice $(77 \pm 10 \mathrm{mg} / \mathrm{dl}$ for WT vs. $69 \pm 6 \mathrm{mg} / \mathrm{dl}$ for MCH1R KO; Marsh et al. 2002). We therefore predict that the reduced body weight gains of MCH1R KO mice upon HF diet might be accompanied by lower triglyceride/free fatty acid levels. Together, these data point at the $\mathrm{MCH}$ system as being involved in the adaptation of the organism to excess caloric consumption.

In summary, our experiments show that the endogenous $\mathrm{MCH}$ system has an important role in regulating energy homeostasis upon high-fat diet consumption. It, however, remains to be described how the $\mathrm{MCH}$ system regulates these processes.

Acknowledgments We would like to thank Dr. Su Qian in Merck for providing us with MCH1R KO mice. We would also like to thank Dr. Qun-Yong Zhou and Dr. Jia-Da Li for helpful discussion and helping us with metabolism assay. This work was supported by grants MH60231 and DA024746 to O.C. S.C. is supported by Davis Foundation Postdoctoral Fellowship Program in Eating Disorders Research supported by Hilda and Preston Davis Foundation.

Open Access This article is distributed under the terms of the Creative Commons Attribution Noncommercial License which permits any noncommercial use, distribution, and reproduction in any medium, provided the original author(s) and source are credited.

\section{References}

Bachner D, Kreienkamp H, Weise C, Buck F, Richter D (1999) Identification of melanin concentrating hormone $(\mathrm{MCH})$ as the natural ligand for the orphan somatostatin-like receptor 1 (SLC-1). FEBS Lett 457:522-524

Bittencourt JC, Presse F, Arias C, Peto C, Vaughan J, Nahon JL, Vale W, Sawchenko PE (1992) The melanin-concentrating hormone system of the rat brain: an immuno- and hybridization histochemical characterization. J Comp Neurol 319:218-245

Chambers J, Ames RS, Bergsma D, Muir A, Fitzgerald LR, Hervieu G, Dytko GM, Foley JJ, Martin J, Liu WS, Park J, Ellis C, Ganguly S, Konchar S, Cluderay J, Leslie R, Wilson S, Sarau HM (1999) Melanin-concentrating hormone is the cognate ligand for the orphan G-protein-coupled receptor SLC-1. Nature 400:261-265 
Chen Y, Hu C, Hsu CK, Zhang Q, Bi C, Asnicar M, Hsiung HM, Fox N, Slieker LJ, Yang DD, Heiman ML, Shi Y (2002) Targeted disruption of the melanin-concentrating hormone receptor-1 results in hyperphagia and resistance to diet-induced obesity. Endocrinology 143:2469-2477

Ferrannini E (1988) The theoretical bases of indirect calorimetry: a review. Metabolism 37:287-301

Huang CQ, Baker T, Schwarz D, Fan J, Heise CE, Zhang M, Goodfellow VS, Markison S, Gogas KR, Chen T, Wang XC, Zhu YF (2005) 1-(4-Amino-phenyl)-pyrrolidin-3-yl-amine and 6-(3amino-pyrrolidin-1-yl)-pyridin-3-yl-amine derivatives as melanin-concentrating hormone receptor-1 antagonists. Bioorg Med Chem Lett 15:3701-3706

Ito $\mathrm{M}$, Gomori $\mathrm{A}$, Ishihara $\mathrm{A}$, Oda $\mathrm{Z}$, Mashiko $\mathrm{S}$, Matsushita $\mathrm{H}$, Yumoto M, Ito M, Sano H, Tokita S, Moriya M, Iwaasa H, Kanatani A (2003) Characterization of MCH-mediated obesity in mice. Am J Physiol Endocrinol Metab 284:E940-E945

Ito M, Ishihara A, Gomori A, Matsushita H, Ito M, Metzger JM, Marsh DJ, Haga Y, Iwaasa H, Tokita S, Takenaga N, Sato N, Macneil DJ, Moriya M, Kanatani A (2010) Mechanism of the anti-obesity effects induced by a novel Melanin-concentrating hormone 1-receptor antagonist in mice. Br J Pharmacol 159(2):374-383

Kawauchi H, Kawazoe I, Tsubokawa M, Kishida M, Baker BI (1983) Characterization of melanin-concentrating hormone in chum salmon pituitaries. Nature 305:321-323

Kokkotou E, Jeon JY, Wang X, Marino FE, Carlson M, Trombly DJ, Maratos-Flier E (2005) Mice with $\mathrm{MCH}$ ablation resist dietinduced obesity through strain-specific mechanisms. Am J Physiol Regul Integr Comp Physiol 289:R117-R124

Lembo PM, Grazzini E, Cao J, Hubatsch DA, Pelletier M, Hoffert C, St-Onge S, Pou C, Labrecque J, Groblewski T, O'Donnell D, Payza K, Ahmad S, Walker P (1999) The receptor for the orexigenic peptide melanin-concentrating hormone is a Gprotein-coupled receptor. Nat Cell Biol 1:267-271

Marsh DJ, Weingarth DT, Novi DE, Chen HY, Trumbauer ME, Chen AS, Guan XM, Jiang MM, Feng Y, Camacho RE, Shen Z,
Frazier EG, Yu H, Metzger JM, Kuca SJ, Shearman LP, GopalTruter S, MacNeil DJ, Strack AM, MacIntyre DE, Van der Ploeg LH, Qian S (2002) Melanin-concentrating hormone 1 receptordeficient mice are lean, hyperactive, and hyperphagic and have altered metabolism. Proc Natl Acad Sci USA 99:3240-3245

Mouri T, Takahashi K, Kawauchi H, Sone M, Totsune K, Murakami O, Itoi K, Ohneda M, Sasano H, Sasano N (1993) Melaninconcentrating hormone in the human brain. Peptides 14:643646

Pissios P, Bradley RL, Maratos-Flier E (2006) Expanding the scales: the multiple roles of $\mathrm{MCH}$ in regulating energy balance and other biological functions. Endocr Rev 27:606-620

Qu D, Ludwig DS, Gammeltoft S, Piper M, Pelleymounter MA, Cullen MJ, Mathes WF, Przypek R, Kanarek R, Maratos-Flier E (1996) A role for melanin-concentrating hormone in the central regulation of feeding behaviour. Nature 380:243-247

Saito Y, Nothacker HP, Wang Z, Lin SH, Leslie F, Civelli O (1999) Molecular characterization of the melanin-concentratinghormone receptor. Nature 400:265-269

Saito Y, Cheng M, Leslie FM, Civelli O (2001) Expression of the melanin-concentrating hormone $(\mathrm{MCH})$ receptor mRNA in the rat brain. J Comp Neurol 435:26-40

Shimada M, Tritos NA, Lowell BB, Flier JS, Maratos-Flier E (1998) Mice lacking melanin-concentrating hormone are hypophagic and lean. Nature 396:670-674

Shimomura Y, Mori M, Sugo T, Ishibashi Y, Abe M, Kurokawa T, Onda H, Nishimura O, Sumino Y, Fujino M (1999) Isolation and identification of melanin-concentrating hormone as the endogenous ligand of the SLC-1 receptor. Biochem Biophys Res Commun 261:622-626

Vaughan JM, Fischer WH, Hoeger C, Rivier J, Vale W (1989) Characterization of melanin-concentrating hormone from rat hypothalamus. Endocrinology 125:1660-1665

Zhou D, Shen Z, Strack AM, Marsh DJ, Shearman LP (2005) Enhanced running wheel activity of both Mch1r- and Pmchdeficient mice. Regul Pept 124:53-63 